\title{
Effects of Underscoring on the Perception of Closure and Intensity in Filmed Events
}

\section{William Forde Thompson}

York University

\section{Frank A. Russo}

Queen's University

\section{Don Sinclair}

York University

\section{Please Cite:}

Thompson, W. F., Russo, F. A., \& Sinclair, D. (1994). Effects of underscoring on the perception of closure in filmed events. Psychomusicology: A Journal of Research in Music Cognition, 13(1-2), 9-27.

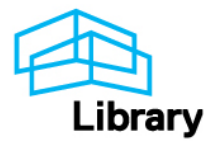




\section{EFFECTS OF UNDERSCORING ON THE PERCEPTION OF CLOSURE IN FILMED EVENTS}

William Forde Thompson

Atkinson College, York University

North York, Ontario, Canada

Frank A. Russo

Queen's University

Kingston, Ontario, Canada

Don Sinclair

Atkinson College,York University

North York, Ontario, Canada

In 3 experiments, we examined the influence of musical underscoring on judgments of closure in filmed events. In Experiment 1, a $12 \mathrm{~s}$ animated episode was judged to end with greater closure if underscoring was strongly closed than if it was weakly closed. This influence of music was implicit: When asked to justify their judgments, participants mainly cited only qualities of the visual information. Experiment 2 provided evidence that music can influence perceived closure in longer film episodes, but it also revealed that musical accompaniment does not always influence judgments of closure. Experiment 3 examined the effect of underscoring for 12 brief film excerpts from a commercial motion picture. Ratings of closure were obtained for 3 conditions: underscores only, films without underscores, and films with underscores. Again, underscoring influenced perceived closure in films. However, ratings of closure were more heavily influenced by visual information than by underscoring. Other effects of closure in film music are discussed.

The practice of coupling film with music can have striking perceptual and aesthetic effects. According to Prendergast (1991), musical underscoring is by far the most effective cinematic tool with which one can intensify the drama in a scene (see also Karlin \& Wright, 1990). Empirical research has confirmed that the addition of musical underscoring to a film can result in significant changes in physiological arousal (Thayer \& Levenson, 1983).

Underscoring may have other important influences on the perception of filmed events. Boltz, Schulkind, and Kantra (1991) found that underscoring can affect one's memory for filmed events. In addition, Cohen (1993) and Marshall and Cohen (1988) reported that musical accompaniment can influence a viewer's interpretation of the affective qualities of visual stimuli. In this paper, we report evidence that underscoring can influence the degree to which actions or events in film episodes are judged to be "complete" or "closed." 
influenced judgments of closure. However, closure ratings for film excerpts with underscoring were more heavily influenced by visual information than by underscoring.

\section{EXPERIMENT 1}

Experiment 1 was designed to establish whether musical closure in underscoring can significantly affect a viewer's sense of closure in a brief film episode. A $12 \mathrm{~s}$ animated film clip was shown under two conditions: with underscoring that strongly conveyed closure and with underscoring that did not convey closure. The manipulation of closure in underscoring was based on the law of return, as described by Meyer (1956; also see Hopkins, 1989; Narmour, 1977, 1990). That is, a musical passage will tend to convey closure if the final event can be construed as a return to parameter values (e.g., pitch class) present at the start of the passage.

In one condition, underscoring was designed to convey closure at melodic and harmonic levels: the first and final notes of the melody were both the tonic, and the first and final chords were both the tonic chord. In the other condition, the underscoring did not convey closure at either melodic or harmonic levels: the first and final notes of the melody were the tonic and sharpened subdominant respectively, and the first and final chords were the tonic and dominant chords respectively. The melody and chord progression used in the two conditions were identical in all other respects. The same animated film clip was shown in both conditions.

\section{Participants}

\section{Method}

There were 24 participants in group 1 and 21 different participants in group 2. Participants were part-time and mature-age students enrolled in an evening course on Intermediate Statistics at York University. The mean age of participants was 28 years. No participants were music majors and most had little or no training in music.

\section{Stimulus construction}

Film. The film clip was $12 \mathrm{~s}$ of animation created with 3-D Studio software by Autodesk, under the control of an IBM compatible computer. The animation clip was a modified excerpt of a demonstration package for the 3$D$ Studio software package. Editing for the modifications were done using Matrox Animation Express software, by Drastic Technologies, Toronto, Canada. The clip involves a technique called morphing, whereby one visual image is transformed smoothly into another visual image through a series of mediating frames. The film excerpt begins with an image of a framed painting of a house. The surface of the painting then is smoothly transformed into an apparent 3-D image of a face (i.e., the face appears to be pushing through the surface of the painting). At the end of the film clip the face is transformed back into the original image of a painting.

Underscores. Two underscores were created using a Roland Sound Canvas synthesizer under the control of a Macintosh $660 / 60$ AV computer, using 
the sequencing software Performer, by Mark of the Unicorn. The two underscores are notated in Figure 1. As can be seen in the figure, the underscores are identical except for the final bar. For both conditions, the melodic line and harmonic accompaniment were played using the oboe and slow strings timbres of the Roland Sound Canvas, respectively.

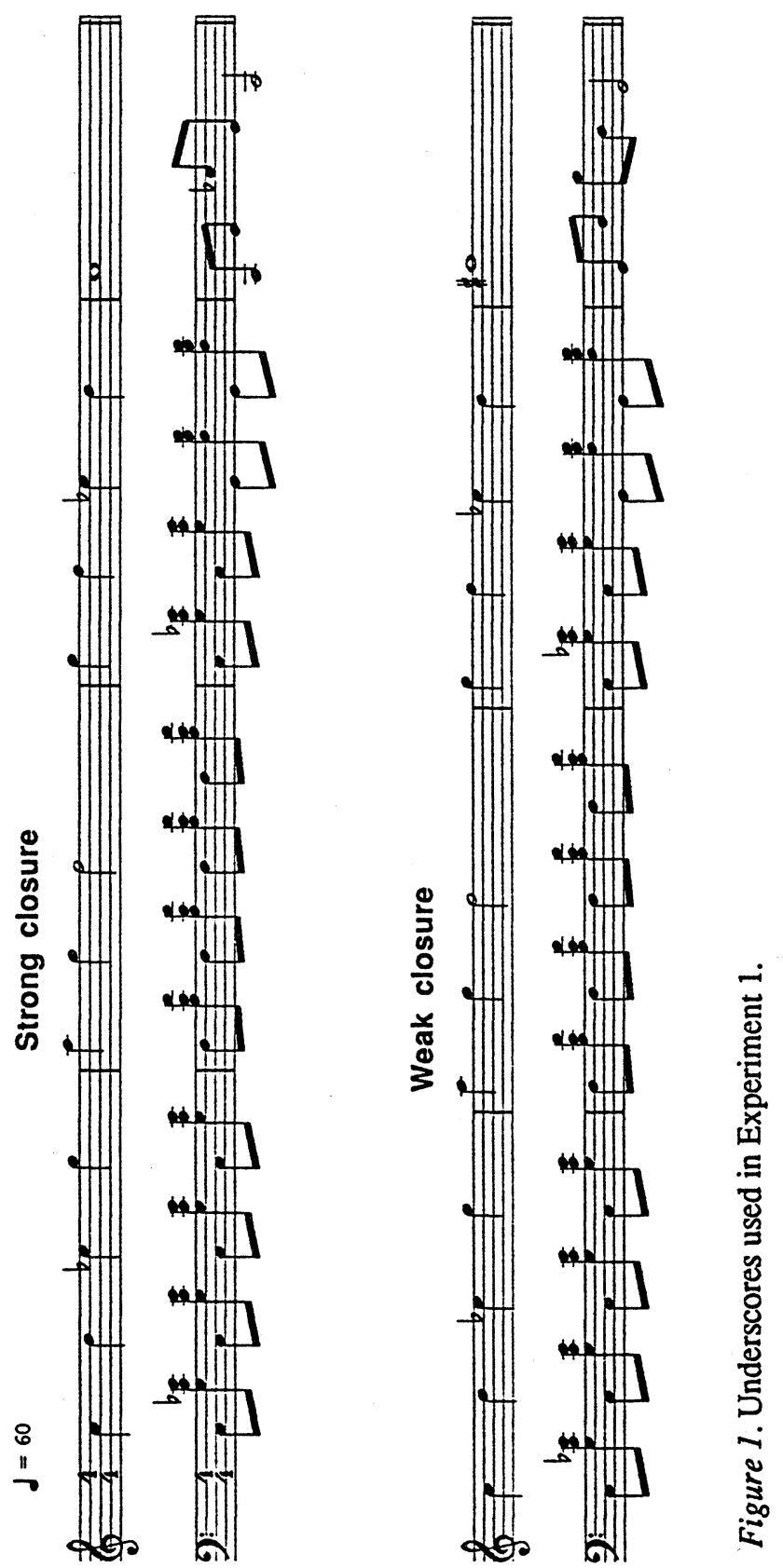




\section{Conditions and Procedure}

There were two conditions. In condition 1 (closure condition), participants were presented the film clip with strongly closed underscoring. In condition 2 (nonclosure condition), another group of participants were presented the film clip with underscoring that did not convey musical closure.

Participants were tested in groups, and were asked to rate the degree of closure conveyed by the film clip. The concept of closure was explained as the sense of finality or completion that is often experienced at the end of an event such as a movie, but that may also be experienced at the end of a brief episode or action. Closure ratings ranged from 1 to 7 . A rating of 1 indicated that the presentation seemed incomplete or unclosed in some way. A rating of 7 indicated that the presentation seemed complete or closed. Participants were also asked to justify their rating in writing.

\section{Results}

Closure ratings were significantly higher if the underscoring was strongly closed than if it was weakly closed, $t(43)=2.48, p<.01$. When underscoring strongly conveyed closure, the mean rating was 4.46 , with a standard error of .36 . When underscoring did not convey closure, the mean rating was 3.00 , with a standard error of .48 .

Participants were rarely aware that underscoring might have influenced their judgments. When asked to justify their ratings in writing, only 5 of the 45 participants mentioned the music, while 23 participants justified their responses on the basis of visual cues. (The others did not mention either component, giving responses such as "very enjoyable" or "seemed to lack direction.") Thus, participants were much more likely to attribute their experience of closure to visual cues than to musical cues, Chi-square $=11.57$, $p<.01$.

\section{EXPERIMENT 2}

Experiment 1 confirmed that by manipulating musical closure in underscoring, it is possible to influence the perceived degree of closure in a short animated film episode. However, the abstract nature and brevity of the film clip may have made it difficult for people to evaluate closure in the visual information, thereby encouraging them to base their judgments on underscoring. Thus, Experiment 2 examined the effect of underscoring on judgments of closure for longer, more realistic film episodes.

\section{Method}

\section{Participants}

Seventy three visitors to the Ontario Science Centre volunteered to participate in the experiment. The mean age of participants was 31 years and the minimum age was 16 years. The number of years of musical training of participants ranged from zero to more than 10 years, with an average of roughly 3 years. 


\section{Stimulus construction}

Films. Two film clips were designed and filmed by the third author. Film clips were constructed using video footage shot on a Panasonic VHS camera. The footage was digitized onto a Macintosh 6100/60 AV computer using the Quicktime movie recording program Fusion Recorder and then edited with the digital-video editing program Adobe Premiere 3.0. The duration of the clips was $30 \mathrm{~s}$ and $34 \mathrm{~s}$ respectively. Clip 1 depicts a person riding a mountain bike along a trail through the woods. The end of the clip shows a fallen tree lying across the trail, but the cyclist is not yet in sight. In clip 2, three people are shown separately walking in an urban setting. At the end of the clip, they converge from different directions and stop, facing each other.

Underscores. Four underscores, two per clip, were created by Garnet Willis, a professional composer for television, film, and theater. The music was created using a MIDI sequencing program, on a Macintosh $6100 / 60 \mathrm{AV}$ computer that controlled MIDI sound generation devices and samplers. Underscores were recorded digitally onto the hard disk using Digidesign Sound Tools, and combined with film clips using Adobe Premiere 3.0. The underscoring for film clip 1 may be classified as "upbeat rock" and included drums, bass guitar, and lead synthesizer. The underscoring for film clip 2 may be classified as "fusion" and included drums, bass guitar, and lead guitar. The two underscores for clip 1 were identical except for the final $6 \mathrm{~s}$. The two underscores for clip 2 were identical except for the final $3.5 \mathrm{~s}$. The composer was instructed to use these final seconds to convey either strong musical closure or nonclosure. Musical closure was effected by ending on the tonic chord of an established key. Nonclosure was effected by ending with a tonally unstable event. The unclosed underscore for film clip 1 ended on the dominant chord, with the melodic line "bending" from the flattened submediant to the flattened seventh. The unclosed underscore for film clip 2 ended on the dominant chord, with the melodic line on the submediant.

\section{Conditions and Procedure}

The 37 participants in group 1 were presented clip 1 with open music and clip 2 with closed music. The 36 (different) participants in group 2 were presented clip 1 with closed music and clip 2 with open music. Participants were assigned to one of the two groups in a random manner, and were tested individually. Each trial consisted of a clip presented on the Macintosh 6100/ $60 \mathrm{AV}$ computer screen, accompanied by underscoring presented through Sennheisser HD-480 headphones. The two film clips were presented in a random order, determined independently for each listener. After each trial, participants were asked to rate on a scale from 1-7 the degree of closure conveyed by the film clip. Participants used the computer keyboard to respond. The rating task was identical to that used for Experiment 1, except that participants were not asked to justify their ratings. 


\section{Results}

Mean ratings of closure in the two film clips, for both closed and unclosed underscoring, are shown in Figure 2. There was a significant effect of underscoring on judgments of closure for film clip $1, t(71)=2.49, p<.01$. However, there was no effect of underscoring on judgments of closure for film clip $2, t(71)=-0.12$, ns.

One possible reason why the effect of music was not consistent for the two film clips is that the closed and unclosed underscores used for clip 1 may have been more discriminable than the closed and unclosed underscores used for clip 2. To test this possibility, 24 new participants rated the degree of closure in each of the four underscores. Participants were again visitors to the Ontario Science Centre, and were tested individually. Ratings were made on a 3-point scale, where 1 indicated that the music was unclosed, 3 indicated that the music was closed, and 2 indicated that the music was not clearly closed or unclosed. Underscores were presented through Sennheisser HD-480 headphones, with no accompanying film clip. The two underscores were presented in a random order determined independently for each listener.

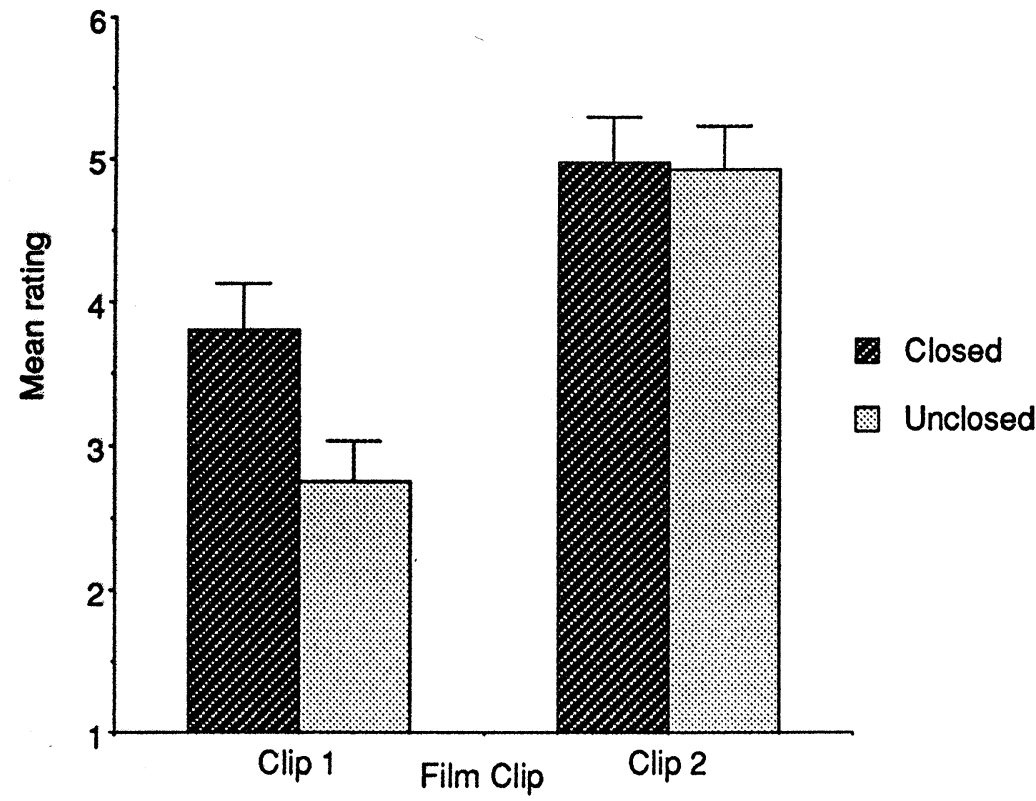

Figure 2. Mean closure ratings for closed and unclosed underscoring, for film clips 1 and 2.

The mean closure rating was higher for closed underscores $(2.71$ and 2.50 for clips 1 and 2 ) than for unclosed underscores (1.21 and 1.33 for clips 1 and 2). A two-way repeated measures ANOVA revealed a significant main 
effect of closure in underscoring, $F(1,23)=50.76, p<.0001$, but no interaction between closure in underscoring and clip, $F(1,23)=0.63$, ns. The lack of an interaction suggests that closed and unclosed underscores were no more discriminable for clip 1 than they were for clip 2. Thus, the null effect of underscoring for clip 2 cannot be attributable to a difficulty in discriminating between closed and unclosed underscoring. Rather, it appears that some aspect of the visual information in clip 2 rendered that clip impervious to influences by underscoring on perceived closure.

\section{EXPERIMENT 3}

Experiment 3 examined the effect of underscoring on judgments of closure for several film episodes excerpted from a commercially successful Hollywood film. Participants were asked to provide closure ratings for both the combined components (film episode with underscoring) and the separate components (i.e., underscoring alone and film episode alone). This procedure allowed us to assess, using multiple regression, the relative influence of visual and underscoring components on perceived closure in film excerpts.

\section{Method}

Participants

There were 17 participants in group 1 and 18 different participants in group 2. Participants were either undergraduate university students, or recent university graduates, with a mean age of 29 years. None of the participants was a music major and most had little or no training in music.

\section{Stimulus construction}

Films. Three criteria were used to select film stimuli. First, the film from which excerpts were taken had to involve a number of discernible episodes with varying degrees of closure. Second, the excerpts had to lend themselves well to the use of underscoring. Third, the meaning of the excerpts had to be interpretable from visual information alone, that is, without dialogue. Using these criteria, 12 excerpts from the film "Clue" (1985) were selected as stimuli. The 12 film excerpts were recorded onto two high quality VHS tapes, such that each tape had a complete set of excerpts. The length of the 12 excerpts ranged from 22 to $46 \mathrm{~s}$ and averaged $32 \mathrm{~s}$. Brief descriptions of each excerpt are provided in Table $1 .^{2}$

Underscores. Twelve underscores were created using a Roland Sound Canvas with Performer software under the control of a Macintosh 660/60 AV computer. Three aims guided the creation of underscores: (a) to mirror the actions and mood of the film excerpts they accompanied (except for the point of closure); (b) to convey a wide range in the degree of closure across the 12 underscores; and (c) to assign the intended degree of closure for underscores in an arbitrary fashion, rather than to match the degree of closure in underscores with the degree of closure in corresponding film excernts. 


\section{Table 1}

Descriptions of the 12 Film Excerpts and Mean Ratings of Closure for the FilmAlone Condition

\begin{tabular}{|c|c|c|}
\hline Film & Description & $\begin{array}{l}\text { rating: } \\
\text { one }\end{array}$ \\
\hline 1 & $\begin{array}{l}\text { A couple in a car approach an eerie castle. } \\
\text { They stop in fear and then proceed } \\
\text { cautiously. }\end{array}$ & 2.35 \\
\hline 2 & $\begin{array}{l}\text { A number of people unwrap ominous gifts. } \\
\text { The episode ends with a man holding a gun. }\end{array}$ & 2.24 \\
\hline 3 & $\begin{array}{l}\text { People are held inside a house. One man } \\
\text { attempts to escape but is threatened by a } \\
\text { guard dog. }\end{array}$ & 3.06 \\
\hline 4 & $\begin{array}{l}\text { People draw straws for partners. The } \\
\text { episode ends with a woman looking at } \\
\text { partner with disgust. }\end{array}$ & 4.47 \\
\hline 5 & $\begin{array}{l}\text { A couple discover a secret passage. They } \\
\text { enter it with caution. }\end{array}$ & 2.59 \\
\hline 6 & $\begin{array}{l}\text { A woman's car has broken down on a dark } \\
\text { road. A second car approaches. }\end{array}$ & 2.00 \\
\hline 7 & $\begin{array}{l}\text { A woman approaches a curtain very } \\
\text { cautiously. She pushes it aside and finds a } \\
\text { broken window. }\end{array}$ & 3.76 \\
\hline 8 & $\begin{array}{l}\text { A woman leaves a house quickly. Flood } \\
\text { lights come on and police arrest her. }\end{array}$ & 3.88 \\
\hline 9 & $\begin{array}{l}\text { A man approaches the entrance to a house. } \\
\text { Guard dogs attack him, but he distracts them } \\
\text { with food. }\end{array}$ & 4.18 \\
\hline 10 & $\begin{array}{l}\text { A woman goes down stairs and enters a dark } \\
\text { room. A rope comes out of the dark and } \\
\text { strangles her. }\end{array}$ & 3.88 \\
\hline 11 & $\begin{array}{l}\text { A man rings a doorbell. He is greeted at the } \\
\text { door. He enters, and the host closes the } \\
\text { door. }\end{array}$ & 4.35 \\
\hline 12 & $\begin{array}{l}\text { People run through a house into a kitchen. } \\
\text { A door is accidentally hit, and a dead body } \\
\text { falls out. }\end{array}$ & 4.65 \\
\hline
\end{tabular}


The 12 underscores were recorded onto a high quality cassette, and then overdubbed onto one of the VHS tapes that contained the film excerpts. The latter recording combined each underscore with a particular film excerpt. Table 2 briefly describes each underscore.

Table 2

Descriptions of the 12 Underscores and Mean Ratings of Closure for the Music-Alone Condition

\begin{tabular}{|c|c|c|c|c|c|}
\hline Underscore & $\begin{array}{l}\text { Ends on } \\
\text { tonic of } \\
\text { established } \\
\text { key }\end{array}$ & $\begin{array}{l}\text { Ends on } \\
\text { strong } \\
\text { beat. Clear } \\
\text { metric } \\
\text { structure }\end{array}$ & $\begin{array}{l}\text { Crescendo } \\
\text { at end }\end{array}$ & Instruments & $\begin{array}{l}\text { Mean } \\
\text { rating: } \\
\text { music alone }\end{array}$ \\
\hline 1 & no & no & no & $\begin{array}{l}\text { choir } \\
\text { piano }\end{array}$ & 3.71 \\
\hline 2 & no & no & no & $\begin{array}{l}\text { horn } \\
\text { flute }\end{array}$ & 2.35 \\
\hline 3 & no & no & yes & $\begin{array}{l}\text { strings } \\
\text { sound effect }\end{array}$ & 3.65 \\
\hline 4 & no & yes & no & $\begin{array}{l}\text { guitar } \\
\text { cymbals }\end{array}$ & 4.29 \\
\hline 5 & no & no & no & $\begin{array}{l}\text { horn } \\
\text { drums }\end{array}$ & 3.29 \\
\hline 6 & yes & yes & no & $\begin{array}{l}\text { bell } \\
\text { drum }\end{array}$ & 6.12 \\
\hline 7 & no & no & yes & $\begin{array}{l}\text { flute } \\
\text { drum } \\
\text { cymbals }\end{array}$ & 3.59 \\
\hline 8 & no & no & no & $\begin{array}{l}\text { strings } \\
\text { drums }\end{array}$ & 2.06 \\
\hline 9 & no & yes & yes & strings & 4.82 \\
\hline 10 & yes & yes & $\begin{array}{l}\text { no } \\
\text { choir }\end{array}$ & pizzicato & 5.88 \\
\hline 11 & yes & yes & no & $\begin{array}{l}\text { nylon guitar } \\
\text { strings }\end{array}$ & 5.88 \\
\hline 12 & no & no & no & $\begin{array}{l}\text { bell } \\
\text { drum } \\
\text { cymbals }\end{array}$ & 3.88 \\
\hline
\end{tabular}




\section{Conditions and Procedure}

Group 1 took part in three conditions. In condition 1 (music-alone), participants were presented the 12 underscores without film. In condition 2 (film-alone), participants were presented the 12 film episodes without underscoring or any other sound. In condition 3 (film-with-music), participants were presented the 12 film episodes with underscoring. Each film listed in Table 1 was paired with the underscore having the same corresponding number in Table 2. The 12 trials within each of the three conditions were presented in random order. The order of conditions presented to participants was: condition 1 (music-alone); condition 2 (film-alone); and condition 3 (film-with-music). For each trial within each of the three conditions, participants provided ratings of closure. Ratings of overall intensity were also collected for each presentation, but these judgments will not be discussed. ${ }^{3}$

We considered the possibility that providing ratings for the music-alone and film-alone conditions might significantly influence ratings for the filmwith-music condition. Thus, a second group of participants (group 2) provided ratings of closure for condition 3 only (film-with-music condition). Mean closure ratings for this group were then compared with the mean closure ratings obtained by group 1 . Closure ratings ranged from 1 to 7 . A rating of 1 indicated that the presentation seemed incomplete or unclosed in some way. For example, the presentation (whether it was music or film or both) might stop just before an anticipated event, or at an otherwise unexpected moment. A rating of 7 indicated that the presentation seemed complete or closed.

\section{Results}

Figure 3 shows mean closure ratings by group 1 for the music condition, the film condition, and the music-with-film condition. Mean closure ratings for the film-alone and music-alone conditions are also shown in Tables 1 and 2 respectively. Examination of mean ratings suggests that the perceived closure in underscores (music-alone) was sometimes greater than, sometimes less than, and sometimes similar to the perceived closure in the film excerpts they accompanied (film-alone). As was the intention in creating the underscores, the degree of closure in underscores did not necessarily correspond to the degree of closure in the film excerpts for which they were composed. The correlation between mean ratings for the film-alone condition and mean ratings for the music-alone condition was not significantly different from zero $(r=.16)$. 


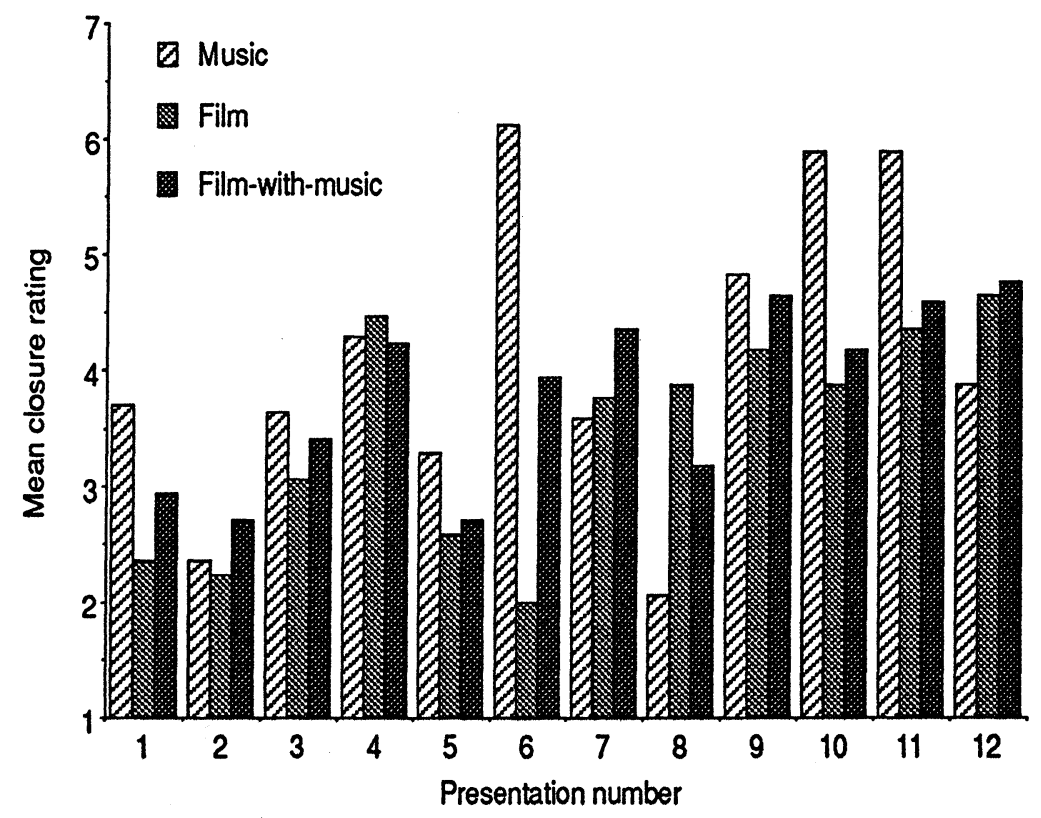

Figure 3. Mean closure ratings for the music condition, the film condition, and the film-with-music condition. The standard error of ratings for music, film, and film-with-music conditions averaged $0.38,0.41$, and 0.44 respectively.

There were three stages in the analysis. First, one-way ANOVAs were conducted for each condition separately. Second, judgments for the filmalone condition were compared to judgments for the film-with-music conditions, using a two-way ANOVA. The latter analysis was done to confirm that underscoring had a statistically reliable influence on perceived closure in the film-with-music condition. Finally, the relative degree of influence of film and underscoring components on judgments for the film-with-music condition was assessed using multiple regression.

\section{Music-Alone Condition}

The main effect of underscore was significant, $F(11,176)=13.63, p<$ .0001 , indicating that listeners with little or no musical background could reliably differentiate the underscores in terms of closure. Two contrast analyses were done to assess the influence of meter and tonality on judgments of closure. From Table 2, it can be seen that five of the underscores ended on a strong beat of a clearly established metric structure. Mean rating of closure for these five underscores (5.40) was significantly higher than that for other underscores (3.22), $F(1,16)=15.45, p<.005$. Among these five under- 
scores, mean ratings of closure were significantly higher for the three underscores that ended on the tonic of an established key (5.96) than for the two underscores that did not end on the tonic of an established key (4.56), $F(1,16)=17.73, p<.001$.

\section{Film-Alone Condition}

The main effect of film excerpt was also significant, $F(11,176)=6.86$, $p<.0001$, indicating that the (silent) film excerpts were perceived to be significantly different from each other in closure. Examination of Table 1 indicates that the highest ratings of closure were assigned to film excerpt 12 , in which a dead body is discovered behind a door. High ratings of closure were also assigned to film 4 (after characters draw straws, a woman gives a comical look of disgust), film 11 (a man is greeted at a door, he enters, and the host closes the door), and film 9 (a man approaches a door where he successfully distracts two vicious guard dogs). Film excerpts assigned low ratings of closure included film 6 (a woman's car stalls, and a second car approaches), and film 2 (characters unwrap ominous gifts).

\section{The Influence of Underscoring on Judgments of Film Excerpts}

To examine whether underscoring influenced judgments for the filmwith-music condition, ratings for the film-alone and film-with-music condition were entered into a two-factor ANOVA. The two factors were music (i.e., film vs. film-with-music), and presentation (the 12 presentations within each condition).

There was a significant main effect of music, $F(1,16)=4.67, p<.05$, and a significant interaction between music and presentation, $F(11,176)=$ $1.88, p<.05$, suggesting that underscoring influenced judgments of closure. The main effect of music indicates that underscoring generally increased mean ratings of closure across the 12 presentations. However, the significant interaction indicates that the effect of underscoring was different for different film excerpts. For example, while underscoring increased ratings of closure for film excerpt $6, F(1,16)=14.45, p<.005$, it decreased ratings of closure for film excerpt $8, F(1,16)=4.59, p<.05$.

\section{Assessing the Relative Contributions of Film and Underscoring}

Examination of Figure 3 suggests that perceived closure in the filmwith-music condition was often a compromise between perceived closure in the separate components. For 8 of the 12 film-with-music presentations, the mean closure rating lies somewhere between the mean closure ratings for the film-alone and music-alone conditions. This observation suggests that both film and underscoring components contributed to judgments of closure in the film-with-music condition.

Correlation and multiple regression were done to assess the relative influence of film and music components on judgments for film-with-music presentations. The 12 mean ratings for the film-with-music condition were significantly correlated with both the 12 mean ratings for the film condition 
( $r=.76, p<.01)$, and the 12 mean ratings for the music condition $(r=.63, p$ $<.01)$. A multiple regression analysis of these means then confirmed that both the film and the music components provided a unique contribution to judgments for the film-with-music condition. When mean ratings for the film-alone and music-alone conditions were entered as predictors of mean ratings for the film-with-music condition, both film and music components had predictive power significantly beyond what could be explained by the other component. The beta weight for the film-alone predictor was .675 ( $p$ $<.001)$ and the beta weight for the music-alone predictor was $.519(p<$ $.005)$. These results suggest that across the 12 film-with-music presentations, judgments were influenced by both film and music components. However, a comparison of the beta weights and correlation values also suggests that judgments of closure were based somewhat more heavily on visual cues than on underscoring. The multiple correlation for the additive model was $.915(p<.0001)$. The strong predictive power of this model suggests that visual and musical components make independent and additive contributions to judgments of closure when those components are combined.

\section{Evaluating the Importance of Exposure to Individual Components}

It is possible that closure ratings for the film-with-music condition were based on closure ratings already assigned for the film-alone and musicalone conditions, rather than on the degree of closure actually experienced for presentations of film-with-music. Thus, we questioned whether mean ratings for the film-with-music condition would have been markedly different had participants not been exposed to the individual components. To address this concern, an independent group of participants provided closure ratings for the film-with-music condition, but not for the film-alone and music-alone conditions. Closure ratings for the two groups were then entered into a two-factor analysis of variance. There was no significant main effect of group, and no significant interaction between group and presentation. Thus, judgments of film-with-music presentations were not significantly affected by whether or not participants had judged music and film components on their own. ${ }^{4}$

\section{Discussion}

The results of this research indicate that it is possible to use underscoring to affect the degree of perceived closure in film episodes. Judgments of closure in films, although strongly influenced by the actions in film episodes, were often affected by underscoring. It is likely that greater influences by underscoring would occur for a musically trained population, or for film excerpts with impoverished visual information (Marshall \& Cohen, 1988).

Experiment 1 indicated that changing just the final note and harmonic accompaniment in underscoring can significantly affect a viewer's sense of closure, or finality, of a filmed event. The musical effect of this change is compatible with the view that closure may be established through the law of 
return (Meyer, 1956). However, the result indicates that the experience of finality produced through musical closure may be attributed to concurrent visual input. In short, underscoring may play a role in determining how a viewer parses temporally structured visual information into "episodes."

Experiment 2 confirmed that musical closure may influence the perceived closure for longer, more realistic film episodes. However, the results also indicate that, for some film episodes, introducing musical closure may not affect the perceived closure of the episode. Evidently, the capacity for music to influence closure in film episodes depends on the characteristics of the visual information. As to the precise nature of this relationship, a number of interpretations are compatible with our findings. One possibility is that when visual information is more engaging, underscoring is less likely to influence perceived closure in film. Another interpretation is that visual closure represents just one possible implication of closure in underscoring. Supporting this idea, recent pilot work (described below) suggested that while the use of closure in underscoring did not influence judgments of closure for film clip 2, it did affect the type of expectations that viewers formed.

Using film excerpts and underscores with varying degrees of closure, Experiment 3 provided a further demonstration that viewers balance both film and underscoring components in their assessment of closure in film episodes. Using multiple regression, it was established that judgments of closure for presentations of film-with-music were well modeled by a linear combination of influences from underscoring and film components. However, considering that participants were exposed to individual components before making judgments of film-with-music components, a cautious interpretation of this result is warranted.

As a subsidiary issue, the results are relevant to understanding the musical conditions that promote closure. In addition to providing support for the law of return, other musical conditions that promote closure were implicated by our findings. According to Meyer (1956), meter and rhythm play an important role in affecting a listener's sense of musical closure. The results of Experiment 3 were compatible with this view, in that ratings for the music-alone condition were higher if underscores had a clear metric structure than if they had an uneven or poorly established metric structure. Meyer (1956) also suggested that tonality is one of the strongest forces in establishing closure in Western music. Again, our results for the music condition were consistent with this view. Underscores ending on the tonic of a clearly established key were judged to have significantly greater closure than other underscores.

\section{Closure and Expectation}

In discussions of musical closure, it is often assumed that our expectations are influenced by the degree of closure (e.g., Hopkins, 1990; Meyer 1956, 1973; Narmour 1990, 1991). If closure has not been established, listeners usually expect a simple continuation of the ongoing material. Impor- 
tantly, however, musical closure does not necessarily imply that the music has ended. According to Hopkins (1990), a point of closure often "prepares the listener for something else: It creates in the listener the expectation that there will be something new...." Only the final point of closure in music "creates the expectation of silence, the expectation that there will be no continuation..." (p. 13).

Extending these ideas, we have recently been exploring whether closure can be used in underscoring to shape the type of expectations that viewers form when watching film episodes. In a pilot study conducted at the Ontario Science Centre, 48 people were individually shown the two film clips described in Experiment 2. For each film, half the participants were shown the film accompanied by music with strong closure, and the other half were shown the film accompanied by music with an unclosed ending. After each presentation, participants were asked to write down a possible continuation of the film clip.

Responses were classified into three types: no expectation of continuation (closure), expectation that the ongoing actions will simply continue (continuation), and expectation that there will be a change in theme or action (new theme). The analysis suggested that closure in underscoring affected the type of expectations formed by viewers. First, expectations of no continuation were higher if the underscoring was closed (29\%) than if it was unclosed (8\%). Second, expectations of a new theme or action were also higher if the underscoring was closed (46\%) than if it was not closed (17\%). Finally, expectations of simple continuation were higher if closure was not established in the underscoring (75\%) than if the underscoring was musically closed $(25 \%)$. These percentages suggest that closure tends to create an expectation of either no continuation, or a change in theme or action, while the absence of closure tends to sustain an expectation of simple continuation. ${ }^{5}$

\section{Conclusion}

Underscoring in film may be used to shape a viewer's sense of closure in episodes. The degree of perceived closure in film episodes, in turn, may have an important impact on a viewer's impression of the film. Perceived closure may affect the perception of continuity or discontinuity between episodes, the type of expectations that are formed, and ultimately one's memory for a film. In nonmusical contexts, closure has been found to influence memory performance (Bonello, 1981; Reeve, Cole, \& Olson, 1986), the perception of duration (Schiffman \& Greist-Bousquet, 1992), and the manner in which people draw inferences (Blanchard-Fields, Coon, \& Mathews, 1986; Peel, 1973). Thus, it is likely that the manipulation of closure in underscoring has ramifications beyond the effects investigated here. 


\section{References}

Blanchard-Fields, F., Coon, R.C., \& Mathews, R.C. (1986). Inferencing and television: A developmental study. Journal of Youth and Adolescence, 15, 453-459.

Bonello, P.H. (1981). The Zeigarnik effect and the recall of geometric forms. Unpublished Doctoral Dissertation, Illinois Institute of Technology, U.S.A.

Boltz, M. (1989). Perceiving the end: Effects of tonal relationships on melodic completion. Journal of Experimental Psychology: Human Perception and Performance, 15, 749-761.

Boltz, M., Schulkind, M., \& Kantra, S. (1991). Effects of background music on the remembering of filmed events. Memory and Cognition, 19, 593-606.

Cohen, A.J. (1993). Associationism and musical soundtrack phenomena. Contemporary Music Review, 9, 163-178.

Gombrich, E.H. (1960). Art and illusion. Princeton: Princeton University Press.

Graesser, A., Woll, S., Kowalski, D., \& Smith, D. (1980). Memory for typical and atypical actions in scripted activities. Journal of Experimental Psychology: Human Learning and Memory, 6, 503-515.

Hopkins, R.G. (1990). Closure and Mahler's music. University of Pennsylvania Press, Philadelphia.

Karlin, F. \& Wright, R. (1990). On the track: A guide to contemporary film scoring . New York: Schirmer Books.

Koffka, K. (1935). Principles of Gestalt Psychology. New York: Harcourt, Brace and World.

Marks, L.E. (1987). On cross-modal similarity: auditory-visual interactions in speeded discrimination. Journal of Experimental Psychology: Human Perception and Performance, 13, 384-394.

Marshall, S.K. \& Cohen, A.J. (1988). Effects of musical soundtracks on attitudes toward animated geometric figures. Music Perception, 6, 95-112.

Meyer, L.B. (1989). Style and music: Theory, history, and ideology. Philadelphia: University of Pennsylvania Press.

Meyer, L.B. (1973). Explaining music. Berkeley, CA: University of California Press.

Meyer, L.B. (1956). Emotion and meaning in music. Chicago: University of Chicago Press.

Mooney, C.M. (1954). A factorial study of closure. Canadian Journal of Psychology, 8, 51-61.

Narmour, E. (1991). The top-down and bottom-up systems of musical implication: Building on Meyer's theory of emotional syntax. Music Perception, 9, 1-26.

Narmour, E. (1990). The analysis and cognition of basic melodic structures. Chicago: University of Chicago Press.

Narmour, E. (1977). Beyond Schenkerism: The need for alternatives in music analysis. Chicago: University of Chicago Press.

Peel, E.A. (1973). Nature of adolescent judgment. New York: Wiley.

Prendergast, R.M. (1991). Film music: A neglected art (2nd ed.). New York: W.W. Norton.

Reeve, J., Cole, S.G., \& Olson, B.C. (1986). The Zeigarnik effect and intrinsic motivation: Are they the same? Motivation and Emotion, 10, 233-245.

Rosner, B.S. \& Narmour, E. (1992). Harmonic closure: Music theory and perception. Music Perception, 9, 383-412.

Schiffman, N. \& Greist-Bousquet, S. (1992). The effect of task interruption and closure on perceived duration, Bulletin of the Psychonomic Society, 30, 9-11.

Smith, B.H. (1968). Poetic closure: A study of how poems end. Chicago: University of Chicago Press.

Snodgrass, J.G. \& Feenan, K. (1990). Priming effects in picture fragment completion: Support for the perceptual closure hypothesis. Journal of Experimental Psychology: General, 119, 276-296.

Thayer, J. \& Levenson, R. (1983). Effects of music on psychophysiological responses to a stressful film. Psychomusicology, 3, 44-54. 


\section{Author Note}

This research was supported by a research grant from the Natural Sciences and Engineering Research Council of Canada, awarded to the first author. We gratefully acknowledge helpful contributions made by Shulamit Mor and anonymous reviewers. We would like to thank Robert Sisinni and James Brooks for their assistance creating the visual stimuli for Experiment 1, and Garnet Willis for creating the underscores for Experiment 2. Reprint requests should be sent to William Forde Thompson at the Department of Psychology, Atkinson College, York University, North York, Ontario, Canada, M3J 1 P3.

\section{Footnotes}

'The types of structures used to produce closure vary in different styles of music. In a relevant study, Hopkins (1990) traced the decline in cadential closure beginning in the late 19th century, and the rise in the use of secondary parameters (e.g., dynamics, texture) to create closure. Such shifts in the choice of style structures are usually encouraged by the ideological climate (Meyer, 1989, p. 211).

'The film "Clue" (1985) was produced by Paramount Pictures Corporation, Hollywood California.

${ }^{3}$ Intensity ratings are available from the first author. A discussion of these ratings is beyond the scope of this paper.

${ }^{4}$ Although the ANOVA did not support an effect of priming with separate components, mean ratings for the music-alone condition (group 1) were more strongly correlated with mean ratings by group 1 for the film-with-music condition $(r=.63)$ than they were with mean ratings by group 2 for the film-with-music condition ( $r=$ .22). The latter correlation was expected to be reduced due to individual differences between the two groups. However, the extent of the reduction raises questions about the importance of priming with music alone, and implicates the need for further research.

${ }^{5} \mathrm{An}$ ex ample of a simple continuation is: "The cyclist will keep riding on the trail." An example of a new theme is: "The cyclist will encounter a bear." If participants wrote two possible continuations, they were classified according to their first response. If participants wrote the clip would continue, but they were unsure what would happen next, their response was coded as a simple continuation. After writing down a possible continuation for each film, participants rated, on a scale from 17 , the intensity of their expectations for future events. Mean ratings were no different for closed and unclosed underscoring. Thus, closure in underscoring did not generally reduce the perceived intensity of expectations. Rather, the effect of closure was to affect the type of expectations formed.

(Manuscript received February, 1993; revision accepted September, 1994.) 